\title{
Transgenia e comunicação da ciência sob o olhar CTS
}

\author{
Cidoval Morais Sousa \\ Danilo Brancalhão Berbel \\ Danilo Rothberg \\ Maria Cristina Piumbato Innocentini Hayashi
}

\section{SciELO Books / SciELO Livros / SciELO Libros}

SOUSA, CM., et al. Transgenia e comunicação da ciência sob o olhar CTS. In HAYASHI, MCPI., SOUSA, CM., and ROTHBERG, D., orgs. Apropriação social da ciência e da tecnologia:

contribuições para uma agenda [online]. Campina Grande: EDUEPB, 2011. pp. 15-40. ISBN 978-857879-187-2. Available from SciELO Books <http://books.scielo.org $>$.

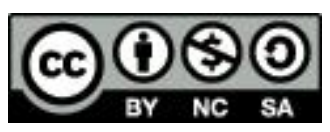

All the contents of this work, except where otherwise noted, is licensed under a Creative Commons Attribution-Non Commercial-ShareAlike 3.0 Unported.

Todo o conteúdo deste trabalho, exceto quando houver ressalva, é publicado sob a licença Creative Commons Atribuição Uso Não Comercial - Partilha nos Mesmos Termos 3.0 Não adaptada.

Todo el contenido de esta obra, excepto donde se indique lo contrario, está bajo licencia de la licencia Creative Commons Reconocimento-NoComercial-CompartirIgual 3.0 Unported. 


\title{
Transgenia e comunicação da ciência sob o olhar CTS
}

\author{
Cidoval Morais Sousa \\ Danilo Brancalhão Berbel \\ Danilo Rothberg \\ Maria Cristina Piumbato Innocentini Hayashi
}

\section{Introdução}

Sob o olhar dos Estudos CTS (Ciência, Tecnologia e Sociedade), a comunicação da ciência pode atribuir distinto status sociológico para emissores, receptores e elementos que influenciam a mediação de significados na relação comunicativa. Se em um ponto inicial o receptor é tido como sujeito passivo e manipulável, repositório vazio à espera de conteúdos plenos e unívocos, no ponto final admite-se que as perspectivas dos indivíduos precisam ser incluídas no próprio processo de formulação de políticas públicas de ciência e tecnologia. No contínuo percurso de 
reconhecimento de capacidades de assimilação e negociação de sentido, o saber possuído pelo sujeito é visto como detentor de diferentes graus de profundidade. Seu conhecimento tanto pode ser tido como conjunto de dados de contexto, referenciados apenas na percepção imediata do ambiente, quanto fruto da experiência acumulada, e neste caso se reconhece que suas vivências podem dotá-lo de expertise de valor inegável, a ser devidamente reconhecida por políticas públicas que busquem legitimidade, eficiência e eficácia.

Atualmente, os organismos geneticamente modificados estão entre os produtos de tecnologias que têm sido enfocados sob vários aspectos, relacionados às diferentes formas de reconhecimento do sujeito pelas abordagens comunicativas. No Brasil, a comunicação de transgênicos tem sido realizada por setores do governo em linguagem técnica e especializada, não acessível a um público mais amplo. O vazio deixado pela comunicação pública tem sido preenchido por empresas e organizações não governamentais, que fazem a defesa de suas perspectivas em abordagens sem pluralismo e equilíbrio. Este estudo examina, através de análise de enquadramento, peças de comunicação produzidas por Monsanto e Greenpeace, a fim de identificar a potencial contribuição trazida por elas ao debate público sobre as alegadas vantagens e desvantagens da disseminação de transgênicos no Brasil. Pode-se indicar que cada um dos emissores constrói narrativas peculiares, a fim de destacar seus argumentos e desqualificar posições contrárias, em um debate fragmentado, com implicações negativas para a cidadania enquanto exercício do direito de liberdade de informação. 
No percurso desenvolvido aqui, em primeiro lugar, são discutidos aspectos da relação entre ciência e comunicação, com a caracterização de conceitos fundamentais para a área de divulgação científica. Em segundo lugar, é delineado o olhar específico dos Estudos CTS para a área. Por fim, peças de comunicação de transgênicos são analisadas, com o objetivo de estimar sua potencial contribuição para o enriquecimento do debate público sobre o assunto.

\section{A comunicação da ciência}

Nos estudos sobre a relação entre ciência e público, são problematizadas duas grandes tendências de comunicação, que podem ser tomadas aqui como referência: as que apontam processos de comunicação em uma única via, desde os cientistas até a sociedade, e nos quais a chave é a disseminação da informação; e aquelas que propõem processos dialógicos, nos quais a participação e a postura ativa do público são o foco de atenção (FARES; NAVA; MARANDINO, 2007).

No contexto das tendências unidirecionais, destacam-se, de um lado, o modelo de déficit, que posiciona o cientista como aquele que sabe, e o público como aquele que tem déficit de saber e, assim, o que sabe emite e o que não sabe recebe passivamente; e, de outro, o modelo contextual, segundo o qual os indivíduos não recebem informação como recipientes vazios (LEWENSTEIN; BROSSARD, 2006). Este último modelo valoriza as experiências culturais e os saberes prévios das audiências e reconhece que quando os conhecimentos científicos ou tecnológicos fazem parte do cotidiano do público, o processo de compreensão é facilitado. 
Já no contexto das tendências dialógicas, também dois modelos se destacam: o modelo de experiência leiga, que valoriza os conhecimentos locais, então considerados tão relevantes para a resolução de problemas científicos e tecnológicos quanto os conhecimentos científicos; e o modelo de participação pública, que parte do compromisso de democratização da ciência e da tecnologia, pressupondo, como condição necessária para o desenvolvimento dessas atividades, a valorização do diálogo entre cientistas e nãocientistas (DURANT, 1999).

A comunicação, neste enfoque, é percebida como intrínseca à ciência e como aquela sem a qual a primeira não existe socialmente. É famosa a frase cunhada por Vessuri $(1987 ; 2002)$ segundo a qual a ciência que não é comunicada não existe. Na perspectiva dos estudos CTS, as elocuções comunicativas são atos de palavra; elas realizam ações, ou, na terminologia da teoria dos atos de palavras, têm uma força ilocucionária que não depende do seu conteúdo proposicional: quando fala, o emissor está fazendo alguma coisa, e não apenas descrevendo determinada situação.

A ideia de que a comunicação e particularmente a fala e a escrita são intrinsecamente processos ativos, tornou possível, de acordo com a autora, entender a comunicação como uma esfera da atividade social de direito próprio, no interior da qual as mensagens não são apenas preservadas ou transmitidas, mas formadas e construídas. Isso, segundo ela, faz reavivar o interesse na comunicação, na medida em que esta inclui estratégias de persuasão. Este modelo abriu as portas para estudos das negociações interativas e da definição de sentido por dois ou mais participantes do processo da comunicação. 
Essa concepção não só assume que as mensagens se modificam na interação, mas que há resultados emergentes - efeitos da interação aos quais os participantes poderiam chegar por si mesmo. $\mathrm{O}$ esbatimento da distinção entre palavras e obras, entre comunicação e ação, tornou emblemáticas quaisquer fronteiras entre, por um lado, a investigação e o trabalho científico e, por outro, a comunicação dos resultados dessa investigação. A comunicação, assim, infiltra a pesquisa científica e é tão relevante para ela como é para as questões relativas a gesto de publicizar seus resultados.

Para Knorr-Cetina (1999), a comunicação das ciências tem cinco dimensões: a) a literária - que pode ser capturada a partir dos produtos escritos das ciências: artigos, descrição de patentes, relatórios de pesquisa e inclui questões como estratégias construtivas e persuasivas e a dimensão histórica; b) a dimensão epistêmica - está diretamente relacionada com a verdade, a facticidade e a objetividade das ciências, uma vez que a comunicação encontra-se implicada em todos os processos de formação de consensos, da definição material e dos significados dos resultados experimentais; c) a dimensão biográfica - considera não apenas as questões epistêmicas, mas também os cientistas; é pela comunicação que se projetam, constroem seu ciclo de credibilidade; d) a dimensão coletiva - considera, particularmente, a comunicação que se desenvolve e resulta de investigações de grupos verdadeiramente globais, em trabalhos que envolvem especialistas e não especialistas e acabam por construir uma nova cultura de comunicação; e) a dimensão da comunicação para público leigo - promulgação através de gráficos, desenhos computadorizados, 
videografias, recursos imagéticos e textuais informativos de toda ordem, que possuem um poder de persuasão maior do que a narração de histórias; fornecem perspectivas abertas e dinâmicas sobre coisas minúsculas e difíceis de descrever; e convertem extensos argumentos em imagens que parecem dizer o que as palavras significam.

Esse último tipo de comunicação, no qual se encaixa o jornalismo científico, não chega a comprometer a ciência genuína, mas cria uma outra dimensão: a ciência popularizada. Nesse sentido, tem função retroativa: os cientistas também aprendem pelo que leem nos jornais, escutam no rádio, veem na TV ou na internet. Além disso, eles se beneficiam com a repercussão pública, que pode, em certa medida, garantir financiamentos, e com a possibilidade de expansão do processo de construção do trabalho científico. Comunicar ciências, nessa perspectiva, não é apenas dar publicidade, traduzir, reconstruir discursos, projetar o conhecimento, mas, principalmente, sinalizar com possibilidades de redução do fosso que existe entre os que conhecem, produzem conhecimento, e os que não produzem e nem têm acesso, numa tradução vulgar do que disse Vessuri (2002).

É preciso reforçar que a comunicação não se constrói a partir dos conceitos prontos, das teorias consensuais, dos modelos acabados; ela tem natureza polifônica, constrói-se pela interação de muitas vozes. A informação não sai do laboratório direto para a publicação num determinado meio. O percurso é complexo, cheio de disputas, interesses que envolvem indústrias, agências de fomento, governos, veículos, e considera, também, públicos diferenciados: 
quem escreve, dizem Lewenstein; Brossard (2006), tem em vista um determinado tipo de público.

Na concepção tradicional, os divulgadores geralmente são vistos (e até se assumem) como mediadores tradutores de conhecimentos especializados, verdades estabelecidas em alguma área do conhecimento, para um público não especializado. E as investigações, por sua vez, também contemplam um modelo de ciências puro, objetivo, provado. Nesse modelo, como frisa Lopes (1997), não há espaço para uma ação criativa e participativa no processo de produção do conhecimento por parte dos divulgadores, nem tão pouco há compartilhamento de poder; quando muito, sobra a tarefa de repetição de simplificações autorizadas ou distorções de "saberes inacessíveis" para um público passivo. No entanto, conforme lembra Weingart (1999), a abordagem dos cientistas à mídia e as repercussões que trazem para as ciências somente podem ser devidamente compreendidas se considerarmos como a popularização serve de intermediária entre as ciências e a sociedade.

\section{Ciência e Estudos CTS}

Estas reflexões se orientam pelos enfoques CTS (ou Estudos Sociais da Ciência e da Tecnologia), um campo que emergiu da crítica ao desenvolvimento científico e tecnológico, e que tem lugar, particularmente, na Europa e nos Estados Unidos, a partir dos anos 1960. A ciência e a tecnologia convertem-se, nessa perspectiva, em parte constitutiva da maioria dos problemas críticos que enfrenta a humanidade e que a coloca em risco, tais como guerra, crise ambiental, doenças e desemprego. Investiga-se a forma pela 
qual os fenômenos técnico-científicos e sociais interatuam e influenciam-se uns aos outros.

Para Cerezo; Luján (2000), os estudos em CTS se ocupam primordialmente da dimensão social da ciência e da tecnologia, tanto do ponto de vista de seus antecedentes como de suas consequências. Pode-se dizer, também, que esses estudos caracterizam-se por reconhecer a complexidade da relação entre a tríade ciência, tecnologia e sociedade, propondo-se a analisar suas recíprocas influências de forma a superar a ingênua aplicação da clássica relação linear entre elas (VALÉRIO; BAZZO, 2006).

Auler (2002) enumera alguns pontos considerados comuns nas pesquisas CTS: relacionar a ciência com as aplicações tecnológicas e os fenômenos na vida cotidiana; abordar o estudo daqueles fatos e aplicações científicas que tenham uma maior relevância social; abordar as implicações sociais e éticas relacionadas ao uso da ciência e do trabalho científico; e adquirir uma compreensão da natureza da ciência e do trabalho. De acordo com a Organização de Estudos Interamericanos (OEI), os estudos em CTS têm entre seus objetivos promover a alfabetização científica mostrando a ciência como uma atividade humana de grande importância social. Entre seus públicos, segundo a OEI, estão jornalistas científicos e receptores da comunicação da ciência através dos meios (HAYASHI; HAYASHI; FURNIVAL, 2008).

A abordagem CTS apoia-se numa visão construtivista, segundo a qual as ciências e a atividade científica são concebidas como produções socioculturais, tanto na dimensão das metodologias e das técnicas, como também das 
temáticas, das teorias e das demais formas de explicação (WORTMANN, 1999). Em outras palavras: o conhecimento científico é o resultado de um processo de criação e interpretação social, e não simplesmente uma revelação ou uma descoberta da realidade. A ciência e seus produtos (literários, técnicos etc) não são a explicação definitiva, acabada do mundo, mas uma das muitas formas de explicá-lo, estruturando como percebemos a natureza. Não há como separar o social do científico, o interno do externo à atividade científica.

Pela primeira vez, a ciência é estudada no seu lugar de produção (laboratório) e entendida como um discurso resultado de processos complexos de negociação e busca de consenso. Quanto maior for a capacidade de articulação e formação de redes, dos atores envolvidos em determinado projeto, tanto maior será a probabilidade de se obter acordos na construção dos significados das teorias propostas. Todo trabalho científico está impregnado de decisões. O fato científico, em si, é resultado da soma de seleções feitas ao longo do processo investigação.

Os produtos da ciência são 'ocasionados' pelas circunstâncias de sua produção, e esse caráter ocasionado se manifesta no papel que assume tudo o que rodeia visivelmente o lugar da pesquisa: os edifícios, os aparatos de medida, os materiais armazenados, as revistas, os livros nas bibliotecas do laboratório, os técnicos especializados e, também, os objetos menos materiais, como os processos de regulação das jornadas de trabalho dos técnicos e as políticas para se conseguir dinheiro para a manutenção das pesquisas (KNORR-CETINA, 1995). 
Pode-se observar que esta visão de ciência não parte dos conteúdos já significados, mas do processo de construção de significados, do lugar onde os significados são negociados em decisões que vão sendo tomadas ao longo do processo de investigação. São decisões que sofrem influência não apenas dos fatores internos, embora o método tenha fortes características internalistas; mas, também, de fatores externos ao ambiente de produção, como as políticas públicas, por exemplo.

Como dizem Latour; Woolgar (1997), a entrada no mundo da ciência e da tecnologia se dá pela porta de trás, a da ciência em construção, e não pela entrada grandiosa, que é da ciência acabada. Se a ciência tem, como diz ele, duas faces - uma que sabe e a outra que ainda não sabe -, é importante ficar com a mais ignorante, com o mínimo possível de ideias sobre aquilo que se constitui ciência. Ao entrar no laboratório, entendido aqui numa perspectiva mais ampla, como o lugar onde o cientista trabalha, o investigador, que opta pela segunda face da ciência, tem a oportunidade de encarar a 'caixa-preta' antes que ela seja fechada.

Se a ciência pronta, como reza a tradição positiva, possui certeza, frieza, distanciamento, objetividade, isenção, a pesquisa, segundo Latour; Woolgar (1997), no seu lócus, apresenta características opostas: é incerta, aberta e está sempre às voltas com problemas 'insignificantes', como dinheiro, instrumentos, capacidade técnica, incapaz de fazer distinções de natureza objetiva. Não prospera desvinculada do coletivo, porque, na essência, é uma grande experimentação coletiva que envolve humanos e não 
humanos (objetos, animais, bactérias), num processo cujo significado é sempre controverso. A ciência pronta não se revela; embora esteja impregnada de decisões.

\section{Lacunas da comunicação pública de transgênicos}

Como se discutiu até aqui, são bastante complexas as questões propriamente políticas envolvidas na adoção de determinadas tecnologias por um país em certo momento. Assim, não se pode negligenciar a dimensão dos desafios a serem enfrentados por uma abordagem comunicativa que se pretenda plural, equilibrada e abrangente. A crítica de peças, ações e instrumentos de comunicação precisa, portanto, ser realizada com foco e especificidade, a fim de minimizar o risco de o analista se orientar por padrões normativos excessivamente idealizados, descabidos diante do limitado propósito das abordagens analisadas. Ou seja, é prudente não fazer exigências muito elevadas ao objeto de pesquisa, porque é possível que este tenha sido produzido com objetivo diverso daquele projetado pelo analista.

Estas ponderações são adequadas para contextualizar os objetos aqui considerados. É possível dizer que nenhum deles se propõe como um guia completo sobre a difusão dos transgênicos no Brasil. Cada um deles se apresenta como um recorte limitado do problema, produzido com propósitos específicos. No entanto, as lacunas identificadas pelas análises aqui apresentadas provêm de um ponto de partida bastante válido, porquanto ancorado na constatação de que são exatamente abordagens como estas analisadas a seguir que permeiam o espaço público de discussão das 
alegadas vantagens e desvantagens da popularização de transgênicos no país. Embora as peças comunicativas aqui consideradas não tenham sido geradas pelos seus emissores para abranger a totalidade do debate, sua fragmentação é notável, colocando-se como defesa publicitária de posições particulares.

Desta forma, se e quando se interessarem por assuntos ligados à popularização dos organismos geneticamente modificados, cidadãos brasileiros que busquem o atendimento de seu direito constitucional à informação poderão se sentir frustrados. A comunicação pública de transgênicos no país possui muitas lacunas e, assim, é difícil indicar razões para crer que o nível de informação e esclarecimento do público em geral sobre essa temática seja satisfatório.

De origem governamental, uma iniciativa proeminente é o sítio da Comissão Técnica Nacional de Biossegurança (www.ctnbio.gov.br). Criada pela lei 11.105, de 24 de março de 2005, a CTNBio tem a finalidade de, segundo seu próprio sítio, "prestar apoio técnico consultivo e assessoramento ao Governo Federal na formulação, atualização e implementação da Política Nacional de Biossegurança relativa a OGM, bem como no estabelecimento de normas técnicas de segurança e pareceres técnicos referentes à proteção da saúde humana, dos organismos vivos e do meio ambiente, para atividades que envolvam a construção, experimentação, cultivo, manipulação, transporte, comercialização, consumo, armazenamento, liberação e descarte de OGM e derivados".

O sítio possui 11 seções, que reúnem informações sobre a própria criação legal da CTNBio; a composição de seus 
órgãos colegiados; aspectos da gestão administrativa das questões sob sua alçada, como pareceres, atas e calendários de reuniões, deliberações e relatórios; leis pertinentes e informações sobre a aprovação de transgênicos (plantas, vacinas e enzimas), em português e inglês; informações sobre eventos ligados à biotecnologia; links para outros órgãos de gestão e fiscalização do setor no Brasil e no mundo; acesso a listas de discussão do setor; e formulário de contato eletrônico.

Há também uma seção de documentos, esta possivelmente a mais capaz de se aproximar do atendimento das demandas de informação do público em geral. Estão ali, por exemplo, o Protocolo de Cartagena sobre Biossegurança, acordo internacional sobre o fluxo de transgênicos entre países, e documentos da União Europeia (em inglês) sobre a regulação do setor.

Mas é notável a ausência de abordagens com linguagem, conteúdo e navegação acessíveis às pessoas não pertencentes a organismos de governo, empresas ou instituições relacionadas. Pode-se objetar que o propósito do sítio não é fornecer informação para não-especialistas, mas o passo seguinte é indagar: se os subsídios não estão ali, onde estarão? Qual é a contribuição de setores governamentais para o esclarecimento dos cidadãos em geral sobre biotecnologia no Brasil? À medida que a esfera pública composta pela internet é um território vasto e em constante transformação, esta questão não pode receber uma resposta conclusiva aqui. Ao menos podemos alegar o desconhecimento de uma fonte nesse sentido. 
Nesse vácuo, prosperam emissores particulares, que produzem informações em abordagens ajustadas à defesa de seus posicionamentos - o que em inglês se conhece por advocacy, termo que leva a pensar na comunicação como ação de se advogar em causa própria. Enquanto são necessárias investigações amplas e sistemáticas para fazer o mapeamento desse espaço, aqui se apresenta uma pequena contribuição possível de trazer indicações de como os desafios de pesquisa se apresentam.

Desta forma, apresentamos uma breve análise de dois vídeos promocionais da organização não governamental Greenpeace e um da multinacional Monsanto. Com esta pequena amostra, apenas procuramos contribuir para apontar aspectos da advocacy que ganha projeção no Brasil e pode, infelizmente, tornar-se mais poderosa à medida que o poder público se omite e deixa de oferecer informações e esclarecimentos devidos segundo a dimensão de compreensão pública de ciência e tecnologia adequada aos sistemas democráticos atuais.

Nesta tarefa empírica, foi empregada a metodologia de análise de enquadramento, muito usada em todo o mundo e cada vez mais frequente nas pesquisas em comunicação no Brasil, que exige a identificação e a caracterização de seleção, ênfase e exclusão de informações e interpretações (ENTMAN, 1993 e 2007; PORTO, 2004).

A seleção indica a presença de certas temáticas em um dado texto, que podem estar associadas à defesa de posições específicas. A ênfase é percebida pela identificação da valorização de significados no título, introdução, repetição e pontos estratégicos salientados por elementos de 
progressão textual. O estudo da ênfase permite sintetizar as perspectivas simbólicas centrais afirmadas por um texto. Já a exclusão é notada pela ausência de aspectos que seriam relevantes para permitir uma compreensão abrangente do fato ou acontecimento em questão. Além disso, como certas temáticas se relacionam a determinados setores sociais, a exclusão de algumas questões pode apontar a prevalência de interesses específicos na formação de enquadramentos.

\section{A defesa do Greenpeace}

Em uma animação em preto-e-branco com a duração de 1'55 que pode ser vista pelo You Tube (http://www. youtube.com/watch?v=mqYqwT6KRZM), o Greenpeace representa transgênicos como plantas com olhos, dentes e orelhas, "criaturas de laboratório, com características muitas vezes desconhecidas". Transgênico é o "peixe com genes de porco, para crescer mais rápido; é a semente de soja que tem genes de vírus e bactérias para resistir a agrotóxicos".

Segundo o Greenpeace, os OGMs causariam contaminação genética e destruiriam a biodiversidade, aumentariam o uso de agrotóxicos no longo prazo e propiciariam o surgimento de superpragas. "Ainda falta muita pesquisa sobre o assunto".

E, "para proteger o interesse comercial das grandes empresas", o governo de Lula seria um dos responsáveis pelo suposto fracasso de um acordo mundial que criaria regras de rotulagem de transgênicos e evitariam a contaminação da "biodiversidade de todo o planeta". 
Segundo a animação, o pequeno agricultor brasileiro teria produção suficiente para alimentar o país e exportar. "O império dos transgênicos pode destruir as pequenas plantações, responsáveis por até $70 \%$ da produção de alimentos no Brasil e você não sabe o que está comendo". Não seria necessário incluir na produção nacional os OGMs, que serviriam apenas para o recolhimento de royalties por empresas estrangeiras.

A Lei de Biossegurança (n. 11.105, de 24 de março de 2005) é enquadrada como negligente quanto à necessidade de estudos de impacto sobre o meio ambiente e saúde humana para cultivo de transgênicos. O governo brasileiro a teria instituído como meio de facilitar o plantio dos organismos modificados. Na época, plantações clandestinas de soja transgênica contrabandeada da Argentina estariam avançando no sul do Brasil e a medida governamental teria servido para regulamentar este plantio ilegal.

Na conclusão, algo como um slogan: "Greenpeace: abra os olhos e feche a boca para os transgênicos".

A animação está comprometida com a oposição aos OGMs, defende essa perspectiva com apelo publicitário e não apresenta um cenário que contribua para o entendimento mais abrangente sobre a temática. 


\section{Óleo de soja transgênico}

"Brasileiros comem óleo de soja transgênico", também acessível pelo YouTube (http://www.youtube.com/ watch? $\mathrm{v}=$ CrlFJQrqr7c ), é uma pretensa reportagem com $10^{\prime} 19$ de duração que denuncia as práticas de rotulagem de empresas de alimentação. "Em recente investigação, o Greenpeace descobriu que as multinacionais Bunge e Cargill estão enganando os brasileiros", segundo o narrador, porque desobedecem à lei segundo a qual a "rotulagem de alimentos transgênicos é obrigatória". A legislação em questão não é especificada. Também não há informações sobre a atuação do Estado na regulação e na fiscalização da circulação de transgênicos.

O Greenpeace se baseia em testes próprios realizados nas portas de fábricas para afirmar que os "óleos Soya e Liza, os mais vendidos no país, são transgênicos". Imagens dos testes são exibidas. Uma representante da organização vestida de jaleco branco prepara uma mistura à base de soja coletada dos caminhões que chegam com o produto. O líquido é separado em três porções, e uma fita é mergulhada. De acordo com o Greenpeace, duas linhas vermelhas nesta fita, que são destacadas posteriormente pelo vídeo, significariam a presença de mais de $1 \%$ de matéria-prima transgênica.

De acordo com a narração, o teste teria sido realizado três vezes, o que garantiria $97 \%$ de precisão. "Todos os testes feitos nas unidades da Bunge em Ourinhos e Dourados e da Cargill em Três Lagoas detectaram transgênicos na soja que estava sendo descarregada. Estas três unidades são grandes produtoras de óleos para o mercado brasileiro". A fábrica de Campo Grande não aceitaria carregamentos transgênicos, 
pois sua produção seria dedicada à exportação. No vídeo, este aspecto é enfatizado, pois o narrador diz:

\begin{abstract}
"As duas multinacionais tratam os brasileiros como consumidores de segunda classe, já que usam o produto rejeitado pelos europeus para alimentar o nosso consumidor". A reação esperada é espelhada pela declaração de um consumidor: "É uma marca que eu vou deixar de usar imediatamente".
\end{abstract}

O vídeo cita uma pesquisa realizada, em 2004, pelo Iser (Instituto de Estudos da Religião) segundo a qual 74\% da população brasileira não rejeitariam produtos contendo transgênicos. O vídeo mostra o símbolo de rotulagem dos transgênicos: um triângulo amarelo com um " $\mathrm{T}$ " preto no centro.

Os OGMs são "uma ameaça conhecida e comprovada para o meio ambiente", segundo o Greenpeace. De acordo com o vídeo, os "transgênicos trazem diversos danos ao meio ambiente, com o aumento do uso de agrotóxicos e o aparecimento de superpragas, além de serem uma ameaça à biodiversidade do planeta".

“O Greenpeace exige que a Bunge e a Cargill, fabricantes dos óleos Soya e Liza, forneçam óleos de soja livre de transgênicos. (...) $\mathrm{O}$ Greenpeace exige também que o governo brasileiro cumpra a lei e garanta ao consumidor o direito à informação", protesta o narrador que, no entanto, não apresenta mais informações sobre os males que atribui aos OGMs. 


\section{Catuti: a semente da mudança}

Com esse título, o vídeo produzido pela Monsanto tem duração de 11'15 e narração da jornalista Ana Paula Padrão. Pode ser visto no sítio da empresa (http://www.monsanto. com.br/sala_imprensa/videos/videos.asp). Representa a história de Catuti, cidade do interior de Minas Gerais produtora de algodão. Segundo o vídeo, as colheitas não estavam mais gerando lucro, quando foi trazida como solução à cidade a "semente da mudança". Com a novidade, os produtores aumentaram sua produção e seu lucro. A economia de outros setores do município também foi beneficiada, como a produção de tecidos e bordados.

O enquadramento é favorável aos transgênicos, então representados como a salvação dos produtores locais.

Antes, segundo a narração do vídeo, Catuti era farta em recursos devido às boas colheitas de algodão. No início da década de 1990, a produção perdeu a força e a região perdeu parte de sua população. "As pragas devoravam a plantação. A abertura para o importado engordava a concorrência. E o que era ouro em Catuti virava pó".

Um técnico agrícola teria sido o responsável por trazer a semente transgênica para a cidade. Ele destaca: "primeira coisa: saber se era verdade isso. Se existia essa proteína que dava essa proteção 24 horas por dia contra ataque de lagartas. E eu consegui ver isso". A transgenia aqui é caracterizada pela presença de uma "proteína", que simbolicamente exerce efeito positivo por relacionar-se com nutrientes essenciais para a alimentação humana. 
“Eu acho que é a volta que a gente está dando por cima, com tecnologias de algodão transgênico para o agricultor familiar", confirma o prefeito de Catuti. Esta é a única citação da palavra "transgênico" no vídeo.

A produção teria saltado de 30 para 200 arrobas por hectare, em um período de cem dias. $\mathrm{O}$ valor de venda saltou de 11 para 24 reais a arroba, segundo o vídeo. "Produto bom vende bem. Ainda mais beneficiado na mini-usina que o grupo de Catuti está começando a operar". O desenvolvimento que os transgênicos teriam trazido para a cidade não se restringiria ao setor do agronegócio, mas englobaria também o beneficiamento do produto colhido. E as mulheres da cidade produziriam tecidos que seriam buscados por consumidores de outras regiões.

"Mas o grande segredo está na qualidade da semente, que resiste às pragas que arrasavam a lavoura", segundo a narração. As supostas qualidades da tecnologia são ressaltadas. "Hoje, com essa tecnologia, a gente tem essa tranquilidade de conduzir essa planta", explica o técnico agrícola.

As plantações são mostradas repetidamente carregadas, com efeitos de iluminação, de maneira que os transgênicos parecem produtos naturais e saudáveis. "Menos agroquímico na lavoura é sinal de proteção ao meio ambiente e, principalmente, ao produtor. José Rodrigues comemora o armazém cheio e tendo usado pouquíssimo inseticida, ao contrário do que acontecia no passado". Este trecho compara o produto geneticamente modificado com o tradicional. Segundo o vídeo, o transgênico seria melhor ao meio ambiente, por não agredi-lo com o uso de pesticidas, e 
para o produtor, que teria maior produção. O termo "agrotóxico" é substituído por "agroquímico" e "pesticidas".

Um produtor afirma que um grande banco com agência no local só financiaria os projetos se utilizassem algodão transgênico. E a prosperidade é geral, com efeito sobre o desenvolvimento social das famílias. $\mathrm{O}$ agricultor José Brasil agora consegue manter as filhas na escola, planeja aumentar a casa e até comprou uma motocicleta. Brasil afirma que os produtores estão "sorrindo porque ( $a$ transgenia) chegou até a gente. Chegou a uma pessoa igual a mim, que é pequeno produtor".

A ênfase do vídeo recai sobre as vantagens da utilização da semente transgênica pelos pequenos produtores. Eles teriam comprovado que a transgenia seria capaz de diminuir o uso de pesticidas e aumentar a produção e o preço do produto. $\mathrm{O}$ algodão geneticamente modificado teria movimentado a região de Catuti, com reflexo positivo em outros setores de sua economia.

$\mathrm{O}$ vídeo, contudo, não explica o que é transgenia ou as razões de a quantidade de agroquímicos supostamente diminuir com o uso dessa tecnologia. Não faz referência à manipulação genética necessária à obtenção de plantas alegadamente mais resistentes a pragas. Não apresenta informações referentes à segurança daquela variação transgênica. Também não contextualiza a discussão da temática dos OGMs, como, por exemplo, questões ligadas à possibilidade de contaminação genética e à esterilidade das sementes produzidas pelos agricultores a partir de uma plantação de transgênicos. 


\section{Conclusões}

Em síntese, os três vídeos analisados estão comprometidos com seus respectivos pontos de vista. Não apresentam informação com pluralidade e não contextualizam a temática por meio da discussão dos diversos posicionamentos relevantes para uma compreensão mais abrangente. Não possuem um propósito propriamente formativo, mas sim de sustentação de argumentos particulares.

Da comunicação pública, proveniente de fontes oficiais, espera-se informação contextualizada, ainda não observada no Brasil em relação à temática da transgenia. Nesse vazio, prospera a advocacy, que, embora tipicamente importante em um ambiente democrático de liberdade de expressão, deveria ser contraposta por abordagens equilibradas, de emissores comprometidos com o atendimento do interesse público segundo critérios publicamente definidos.

Tais estratégias comunicativas de advocacy confrontam a especificidade da comunicação da ciência que, sob o olhar CTS, deveria ser realizada com atenção sobre as repercussões das decisões implícitas em determinadas escolhas de política científica e tecnológica, com contexto e profundidade sobre os antecedentes que justificam certas opções, alternativas possíveis, conflitos envolvidos e meios de negociação, resultados esperados, custos e retornos devidos etc. Na ótica CTS, a pesquisa científica como atividade de natureza social não traz apenas descobertas, mas amplia exatamente o leque de escolhas possíveis para a decisão política. Ora, como toda política pública, a política de ciência e tecnologia também precisa, em um sistema 
democrático, estar sujeita a escrutínio atento por meio das instituições apropriadas. Sob o entendimento do modelo participativo de comunicação da ciência, a tarefa das abordagens comunicativas é justamente o de prover informação que subsidie o diagnóstico de vantagens e desvantagens da adoção de determinada tecnologia. São escolhas que devem ser avaliadas inclusive em contraste com a possível rejeição de outras tecnologias que, sem a vigilância pressuposta por esse modelo, poderiam passar desconhecidas (tal pode ser o caso, por exemplo, das tecnologias de cultivo de alimentos conhecidos como orgânicos, que têm sido ignoradas quando o debate público se reduz à crítica ou defesa de transgênicos). Mas tais complexidades tendem a ser deixadas de lado quando se constrói a abordagem publicitária típica da defesa de posicionamentos particulares. A advocacy da informação contraria os princípios da comunicação sob o olhar CTS.

Em síntese, enquanto Greenpeace recorre a estereótipos de fácil identificação e caricaturas para propagar informações superficiais e incompletas, Monsanto recria livremente a história de uma comunidade local para oferecê-la como caso supostamente emblemático das populações que teriam sido salvas da fome e da pobreza pelo "milagre" da transgenia. Ao passo que essas peças de comunicação têm o objetivo de repercutir as perspectivas de seus emissores sobre o assunto, oferecem uma contribuição limitada como fundamento para compreender as escolhas implícitas nas atuais políticas públicas que regulam a expansão de transgênicos no mercado brasileiro. A falta de informação plural pode gerar dúvidas e incertezas e não favorece a afirmação do direito civil de liberdade de informação. 


\section{Referências}

AULER, D. Interações entre Ciência-TecnologiaSociedade no contexto da formação de professores da ciência. Tese de doutorado. Centro de Educação, Universidade Federal de Santa Catarina, 2002.

CEREZO, J. A. L.; LUJÁN, J. L. Ciencia y política del riesgo. Madrid: Alianza Editorial, 2000.

DURANT, J. Participatory technology assessment and the democratic model of the public understanding of science. Science and Public Policy, v.26 n.5, p.313-319, 1999.

ENTMAN, R. M. F: Toward Clarification of a Fractured Paradigm. Journal of Communication, v.43, n.4, p.51-58, 1993.

ENTMAN, R. M. F: Framing bias: media in the distribution of power. Journal of Communication, v.57, n.1, p.163-173, 2007.

FARES, D. C.; NAVAS, A. M., MARANDINO, M. Qual a participação? Um enfoque CTS sobre os modelos de comunicação pública da ciência nos museus de ciência e tecnología. X Reunión de la Red de Popularización de la Ciencia y la Tecnología en América Latina y el Caribe (RED POP - UNESCO) y IV Taller "Ciencia, Comunicación y Sociedad". San José, Costa Rica, 2007. 
HAYASHI, M. C. P. I.; HAYASHI, C. R. M.; FURNIVAL, A. C. M. Ciência, tecnologia e sociedade: apontamentos preliminares sobre a constituição do campo no Brasil. In: SOUSA, C. M.; HAYASHI, M. C. P. I. Ciência, tecnologia e sociedade: enfoques teóricos e aplicados. São Carlos, SP: Pedro e João Editores, 2008.

KNORR-CETINA, K. D. Los estudios etnográficos del trabajo científico: hacia una interpretación constructivista de la ciencia. In: IRANZO, J. M.;BLANCO, J. R.; GONZALES DE LA FE, M. T.;TORRES, C.; COTILLO, A. (Coords.) Sociología de la ciencia y la tecnología. Consejo Superior de Investigaciones Cientificas: Madrid, 1995.

KNORR-CETINA, K. D. A Comunicação na Ciência. In: GIL, F. (Org.). A Ciência Tal Qual se Faz. Lisboa: Edições João Sá da Costa, 1999. p.375-393.

LATOUR, B.; WOOLGAR, S. A vida de laboratório. Rio Janeiro: Relume Dumará, 1997.

LEWENSTEIN, B.V.; BROSSARD, D. Assessing Models of Public Understanding in ELSI Outreach Materials U.S. Department of Energy Grant DE-FG02-01ER63173: Final Report. Cornell: Cornell University. 2006.

LOPES, M. M. Resta algum papel para o (a) educador (a) ou para o público nos museus? Boletim do CECA - Brasil, ano I, n.0, p.01-04, mar. 1997. 
PORTO, M. Enquadramentos da mídia. In: RUBIM, Antonio A. C. (org.) Comunicação e política - conceitos e abordagens. São Paulo: Unesp; Salvador: Edufba, 2004.

VESSURI, H. La Revista Cientifica Periférica: El caso de Acta Científica Venezolana. Interciencia, v.12, n.3, p.124134, 1987.

VESSURI, H. Ciencia, tecnología y desarrollo: una experiencia de apropriacón social del conocimiento. Interciencia, Caracas, v.27, n.2, p.88-92, 2002.

VALÉRIO, M.; BAZZO, W. A. O papel da divulgação científica em nossa sociedade de risco: em prol de uma nova ordem de relações entre ciência, tecnologia e sociedade. Revista Ibero Americana de Ciência, Tecnologia, Sociedad e Inovación, n.7, set-dez, 2006. Disponível em: $<$ http://www.oei.es/revistactsi/numero7/articulo02b.htm>. Acesso em: 20. out. 2007.

WEINGART, P. Science and the Media. Research Policy, v.27, n.8, p.869-879, 1999.

WORTMANN, M. L. C. Olhando para a educação em ciência a partir dos estudos culturais. 1999 (monografia). p.1-20. 